\title{
QUANDO A ESCOLA NÃO FAZ PARTE DA BIOGRAFIA: DEPOIMENTOS DE VIDA EM HOMESCHOOLING
}

\section{FABIANA FERREIRA PIMENTEL KLOH}

Universidade do Estado do Rio de Janeiro

RESUMO

\section{ABSTRACT}

O estudo objetiva analisar as motivações das famílias adeptas de homeschooling no Brasil, além das justificativas que aqueles que anseiam pela regulamentação legal desta modalidade de educação apresentam para, em suas biografias, excluir a escola enquanto espaço formativo. Pretende-se compreender as razões da resistência à escola obrigatória, na contramão da hegemonia dessa instituição. Trata-se de uma pesquisa qualitativa, de caráter histórico, que utilizou, como fonte, transcrições das notas taquigráficas de audiências públicas realizadas no Congresso Nacional, em 2013. Partindo de referências teóricas que observaram a educação domiciliar, na história do século XIX, em nosso país, contidas em Vasconcelos (2005), bem como das críticas sociológicas à escola, enquanto caminho comum, emitidas por Illich (1973), procedeu-se à análise dos depoimentos de pessoas que, afastando a escola de suas biografias, justificam sua opção por espaços formativos não formais. Extraem-se dessas falas biográficas manifestações da sociedade sobre o assunto, além de motivos pessoais, mas fundamentados, dessa escolha. Foi possivel constatar que a opção por homeschooling constitui um fenômeno crescente no Brasil e que os adeptos dessa modalidade de educação domiciliar esperam por maior segurança jurídica, quanto à observância de seu direito de opção à forma de prover a educação da família. Palavras-chave: Homeschooling. Educação domiciliar. Escola obrigatória. Hegemonia da escola. Educação em casa.

\section{WHEN SCHCOOL IS NOT PART OF THE BIOGRAPHY: LIFE TESTIMONIALS ON HOMESCHOOLING}

The study aims to analyze families' own motivation for adopting homeschooling in Brazil and the justifications for the legalization of such type of schooling by those who, in their biographies, want to exclude school as educational formative space. The objective is to understand the reasons for resistance to mandatory schooling against the hegemony of this institution. It is a qualitative historical research, which has used as its main research tool note transcrip- 
tions in shorthand taken in public audiences that happened in the National Congress in 2013. The theoretical references are studies on homeschooling in Brazil in the XIX century (VASCONCELOS, 2005) and sociological critics to school as a common path (ILLICH, 1973). The research then proceeded to the analysis of peoples' testimonies that, by setting aside school from their biographies, justify their option for non-formal educational formative spaces. From their testimonies it were extracted general society manifestations of reasons for such option that go beyond the level of personal, individual reasons. The option for homeschooling is a growing phenomenon in Brazil, and that those in favor of such type of education wait for legal proceedings towards the guarantee of their right to choose the schooling system they prefer for their families.

Keywords: Homeschooling. Mandatory Schooling. School Hegemony. Home Education.

\section{RESUMEN CUANDO LA ESCUELA NO HACE PARTE DE LA BIOFRAFÍA: TESTIMONIOS DE VIDA EN HOMESCHOOLING}

El objetivo de este estudio es el análisis de las motivaciones de familias que se unieron al homeschooling en Brasil, además de las justificativas de aquellos que añoran por la reglamentación legal de esta modalidad de educación, en sus biografias, excluir la escuela como espacio de formación. Se busca comprender las relaciones de resistencia a la escuela obligatoria y contra la hegemonía de esta institución. Es una investigación cualitativa de carácter histórico, que utilizó como fuente, transcripciones de las notas taquigráficas de las audiencias públicas en el Congreso Nacional en 2013. A partir de las referencias teóricas que han observado a la educación en el hogar, en la historia del siglo XIX en nuestro país (Vasconcelos, 2005) y la crítica sociológica de la escuela como camino común (Illich, 1973), se procedió al análisis de los testimonios de las personas que, alejando la escuela de sus biografias, justifican su elección de espacios formativos informales. Sacamos de estos testimonios biográficos manifestaciones de la sociedad sobre el tema, además de los motivos personales para tomar esa decisión. Fue posible constatar que la elección de la educación en el hogar, homeschooling, constituye un fenómeno cada vez mayor en Brasil y los adeptos de esta modalidad de educación esperan una mayor seguridad jurídica, en cuanto al cumplimiento de su derecho a elegir la forma de proporcionar educación para la familia.

Palabras clave: Homeschooling. Educación en el Hogar. Escuela Obligatoria. Hegemonía de la Escuela. Educación en la casa. 


\section{No princípio... fez-se a resistência}

Maria vai com as outras... Quando Sylvia Orthof (1985) criou essa história, voltada para o público infantil, muito provavelmente inspirou-se no ditado popular que indica que "maria-vaicom-as-outras" são as pessoas sem personalidade, sem opinião própria, que acabam sempre concordando com tudo o que thes falam. Talvez soubesse que essa primeira "Maria sonsa" fosse inspirada nas damas de companhia da rainha Maria I, no início do século XIX, que costumava passear às margens do rio Carioca, no antigo bairro de Águas Férreas, ${ }^{1}$ levada pelas mãos de suas damas de companhia, donde o povo dizia: Maria vai com as outras (GERSON, 2015). Como louca, a rainha não se guiava sozinha, mas sim pelos caminhos que as "outras", suas companhias, lhe diziam.

Essa é uma possibilidade (das muitas que podem existir) de se compreender o desejo de certas famílias no Brasil desejarem excluir a escola de suas biografias, enquanto espaço formativo exclusivo. Não querem ser "mariavai-com-as-outras". Não querem ir pra escola somente porque "todos vão". Querem ir "para onde caminha seu pé" (ORTHOF, 1985, p. 32) como a ovelha Maria da Sylvia.

Compreender as motivações das famílias adeptas de educação domiciliar em nosso país, mesmo diante da não previsão legal desta modalidade de ensino, é o objetivo desse trabalho. Trata-se de um recorte do tema mais amplo que busca compreender como os poderes Legislativo e Judiciário brasileiros vêm tratando o assunto.

Em meio às pesquisas a respeito do tema no Poder Legisltivo, uma das fontes a que se teve acesso foram as duas audiências públicas sobre o assunto na Câmara dos Deputados. Cabe registrar, mesmo sem a intenção de discutir aqui, que o debate sobre a educação domiciliar e a

1 Atualmente, o bairro que se chamava Águas Férreas é denominado de Cosme Velho. tentativa do Legislativo, em inserir sua previsão no ordenamento jurídico pátrio, já remonta a 1994, quando o Projeto de Lei $n^{\circ} 4.657 / 94$ pretendia regulamentar o ensino domiciliar de primeiro grau (KLOH, 2014). Alguns frustrados projetos de lei depois, que não lograram êxito em instituir oficialmente a educação domiciliar, no país, em 08 de fevereiro de 2012, o deputado Lincoln Portela (PRB/MG) apresentou na Câmara dos Deputados uma nova proposta para a regulamentação desta modalidade de educação. Dentro dos trâmites de análise deste projeto de lei, foram realizadas duas audiências, que objetivam colher a opinião pública sobre o assunto em debate. Uma das audiências públicas foi realizada na Comissão Legislativa Participativa, no dia 12 de junho de 2013, e, a outra, na Comissão de Educação, no dia 12 de novembro de 2013 (KLOH, 2014).

Em ambas as audiências, foram ouvidos alguns pais e filhos, ${ }^{2}$ adeptos de homeschooling, que expressaram suas razões e expectativas quanto à educação domiciliar no Brasil. Aí reside o foco de análise deste artigo. Quais as motivações das famílias adeptas de homeschooling $^{3}$ no Brasil? Quais as justificativas dessas pessoas para, em suas biografias, desejarem excluir a escola enquanto espaço formativo exclusivo? Quais as razões para a resistência dessas famílias à escola obrigatória? Respondidas essas questões, pretende-se traçar um perfil do que esperam as famílias homeschoolers, em nosso país. Investigar suas biografias, através de seus depoimentos públicos, permitirá compreender o que motiva as pessoas a resistirem à escola como espaço de formação.

2 Embora também tenham tido voz nas audiências públicas, representantes do Executivo e do Legislativo, neste artigo, somente serão abordadas as falas das famílias defensoras da possibilidade de inserção da educação domiciliar como modalidade válida e reconhecida de educação no Brasil.

3 O termo educação domiciliar em inglês, homeschooling, também é bastante comum, mesmo entre os brasileiros, para designar essa modalidade de educação, motivo pelo qual, em algumas vezes, poderá ser referido desta maneira no artigo. 
Antes de existir uma instituição responsável pela educação, a prática comum era que as próprias famílias fossem as provedoras da tarefa de educar, de transmitir conhecimentos, ensinar as primeiras letras e introduzir no mundo cultural (KLOH, 2014). Com o tempo, o processo de estatização da escola se intensificou. Não só crianças livres, mas também as meninas, os pobres e até os escravos eram atingidos pelo fenômeno da instrução. Assim, gradativamente, as escolas foram se tornando públicas, havendo, inclusive, previsão de sanções contra os pais que não cuidam da educação dos filhos (MANACORDA, 2010).

Não muito distante na história do país, a educação doméstica constituiu uma prática de importância. Vasconcelos (2008, p. 19) indica que é no século XIX que isso acontece e que essa era uma forma recorrente de educação nas classes mais abastadas do Brasil Imperial. A educação doméstica:

era aquela que ocorria na Casa do aprendiz, na esfera privada, na qual os pais contratavam, mediante sua livre escolha, os mestres, os conteúdos e as habilidades a serem ensinados a seus filhos, no tempo e disposição exclusivamente determinados pela Casa. Essa modalidade de educação tinha como agente, [...], os professores particulares, os preceptores, os parentes ou agregados e, ainda, padres que ministravam aulas-domésticas. (VASCONCELOS, 2005, p. 17)

Não obstante, da mesma forma que o século XIX permitiu uma ampliação sem precedentes da prática de educação doméstica, esta também vem se fragilizando diante das pressões do Estado e cedendo lugar à escola formal, "que surge tanto como transformação do sistema vigente quanto como negação do espaço doméstico da educação" (VASCONCELOS, 2005, p. 223).

No século XX, a escola procurou se desvencilhar não só da família, mas também da Igreja, tornando-se expressão isolada da centraliza- ção estatal, no que se refere à educação, e, assim, a educação doméstica do século XIX cede espaço para a educação escolar, institucionalizada no século XX.

$\mathrm{Na}$ contramão da hegemonia da escola, surgem vozes contrárias a essa naturalização do ensino institucionalizado, realizado exclusivamente no ambiente escolar. E os representantes dessas vozes junto ao Poder Legislativo "gritam", pela propositura de leis, para que a educação domiciliar possa figurar como uma opção válida e reconhecida no cenário da educação nacional.

Eis, portanto, a fonte de pesquisa desse artigo: audiências públicas realizadas no âmbito de um dos projetos de lei propostos para a tentativa de regulamentação desta modalidade de educação no país.

Segundo Flach (2009), "tanto a Constituição Federal de 1988, como a Lei de Diretrizes e Bases da Educação Nacional, Lei n 9.394/96, prevêem a obrigatoriedade e gratuidade da escola pública para o ensino fundamental" (FLACH, 2009, p. 514).

A partir dos depoimentos de famílias adeptas de homeschooling no Brasil, traça-se o perfil daqueles que afastam a escola de suas biografias, realizando-se uma análise documental das notas taquigráficas das audiências públicas realizadas pela Câmara dos Deputados, no âmbito do Projeto de Lei $n^{\circ} 3.179 / 12$ (BRASIL, 2012), objetivando compreender o princípio, o meio e o fim da resistência à escola obrigatória.

\section{No meio... as famílias que resistem}

Quando a hegemonia da escola se consolidou no século XX, a educação oferecida por ela passou a sofrer fortes críticas desencadeadas por vários motivos: i) movimento social de contestação à escola, com repercussão no mundo operário, em especial a onda de protestos por reformas no setor educacional (Movimento 
Maio de 1968), em Paris; ii) trabalhadores em busca de processos de promoção social com soluções educativas em oposição ao modelo escolar; iii) auge de um pensamento pedagógico alternativo à escola, que tiveram como expoentes, por exemplo, Paulo Freire e Ivan Illich; e iv) crítica sociológica à escola através da obra de Pierre Bourdieu e Jean Claude Passeron (CANÁRIO, 2002, p. 141).

Pode-se destacar, dentre os críticos do modelo hegemônico da educação escolar obrigatória, Ivan Illich e John Holt. Em apertada sintese, Illich afirma que o "fanatismo pela escola" possibilita serem explorados duplamente, seja com a crescente aplicação de verbas públicas para a educação de uns poucos, seja por permitir uma crescente aceitação de controle social (ILLICH, 1973, p. 30). Segundo ele, a escolarização obrigatória, igual para todos, é economicamente impraticável, além de polarizar a sociedade, bem como disseminar a ilusão de que o que aprendemos é resultado do ensino quando, na verdade, a maioria das pessoas adquire a maior parte de seus conhecimentos fora da escola (ILLICH, 1973, p. 34-37).

Já John Holt ${ }^{4}$ crê que a eliminação da escolaridade obrigatória é necessária para a construção de uma sociedade mais humana, tendo em vista que, cada criança tem uma necessidade "inata e insaciável" de compreender o mundo e qualquer tentativa para regular ou controlar esta necessidade reprime a aprendizagem, já que as escolas seriam "prisões" para as crianças, pensadas não para educá-las, mas para mantê-las "sob controle e fora do caminho dos adultos" (RIBEIRO, 2011, p. 66).

Baseados em argumentos dessa natureza, despontam no Brasil algumas famílias que, resistindo à escola obrigatória, mantêm seus filhos na modalidade homeschooling e tentam convencer o legislativo nacional a introdu-

4 Humanista da ala política esquerda e professor da Universidade de Harvard (RIBEIRO, 2011, p. 65). zir, na Lei de Diretrizes e Bases da Educação Nacional (BRASIL, 1996), norma que garanta a possibilidade da educação domiciliar. Em uma dessas tentativas, o Projeto de Lei $n^{\circ} 3.719 / 12$ (BRASIL, 2012), essas famílias puderam expor suas motivações nas audiências públicas que, analisadas, permitem traçar o perfil da resistência à escola obrigatória.

De acordo com o Regimento Interno da Câmara dos Deputados, audiência pública constitui uma reunião que pode ser realizada em conjunto com a sociedade civil para instruir matéria legislativa em trâmite, bem como para tratar de assuntos de interesse público relevante, atinentes à sua área de atuação, mediante proposta de qualquer membro ou a pedido de entidade interessada (BRASIL, 2014b, p. 158).

Nos trâmites do Projeto de Lei $n^{\circ} 3.719 / 12$ (BRASIL, 2012), aconteceram duas audiências públicas, uma em 12 de junho de 2013, na Comissão de Legislação Participativa, e outra em 12 de novembro de 2013, na Comissão de Educação.

$\mathrm{Na}$ audiência pública da Comissão Legislativa Participativa, foram ouvidos, enquanto representantes de famílias adeptas de homeschooling, o Sr. Ricardo lene Dias e o Sr. Alexandre Magno Fernandes Moreira, ambos da Associação Nacional de Educação Domiciliar (ANED), o pedagogo Fábio Stopa Schebella, o professor da Faculdade de Educação da UnB, Remi Castioni, o sociólogo André de Holanda Padilha Vieira e a doutora em Educação pela PUC/SP, Elizângela Treméa Fell, todos eles apresentando argumentos em prol da regulamentação legal da educação domiciliar no Brasil.

Para o sociólogo Ricardo lene Dias, o debate e a regulamentação permitirão que as famílias não mais sejam processadas por uma interpretação de lei e para que deixem de se sentir ameaçadas. Para ele, não se pode permitir que tirem de um pai a guarda de um fitho ou o mandem para a cadeia, pelo "simples 
fato de ele estar cuidando dos filhos" (BRASIL, 2014a, p. 23). Além de publicitário e membro da ANED, Ricardo Dias é adepto de homeschooling com seus filhos. Segundo ele:

para a gente entender muito bem o processo de Educação Domiciliar, precisamos 'desescolarizar' a nossa mente. Está no inconsciente coletivo a questão de que a escola faz parte da nossa sociedade, mas não foi sempre assim. Nem sempre a escola como conhecemos hoje fez parte da nossa sociedade. [...] a humanidade viveu muitos séculos antes disso, sem esse tipo de escola. Então, precisamos abrir a nossa mente para entender que a educação não é feita só na escola (BRASIL, 2014a, p. 24).

A propósito, a filha de Ricardo Dias, Lorena Dias, protagonizou, em abril de 2015, a manifestação midiática sobre o assunto, tendo em vista sua aprovação no Exame Nacional de Cursos, mesmo tendo sido educada através da modalidade de educação domiciliar. Segundo reportagem de Gabriela Portilho,

Uma decisão inédita da justiça reacendeu o debate sobre a educação domiciliar no Brasil. 0 Tribunal Regional Federal da 1a Região, em Brasília, permitiu, por meio de liminar, que a jovem Lorena Dias, 17 anos, obtenha o certificado de conclusão do Ensino Médio - mesmo tendo feito os estudos em casa (com seus pais em vez de professores, de 2011 a 2014). Por meio do ENEM, a jovem foi aprovada no curso de jornalismo da Universidade de Brasília (UnB) e está frequentando as aulas (PORTILHO, 2015).

Para Lorena Dias, a educação domiciliar pode ser resumida na seguinte frase: "você não precisa de uma escola para estudar nem de um professor para aprender" (BRASIL, 2014a, p. 24).

A defesa da educação domiciliar parece passar, necessariamente, por uma crítica à instituição escolar e, nesse tom crítico, Ricardo Dias cita o livro "Pinóquio às avessas", ${ }^{5}$ no

5 O livro "Pinóquio às avessas" é de autoria de Rubem Alves, com ilustrações de Maurício de Sousa. A sinopse aponta para o perigo que correm nossas crianças, qual, ao invés do boneco de madeira precisar ir à escola para se tornar um menino de verdade, um menino de verdade entra na escola e se torna um menino de madeira, já que lhe foi tirada a "capacidade de questionar, de brincar, de expandir sua criatividade, de buscar o conhecimento" (BRASIL, 2014a, p. 26).

As famílias que optam por uma educação desescolarizada são provocadas a se manifestar sobre os motivos que as levam a "ir contra a maré" da escola obrigatória. Ricardo Dias diz que não há um único motivo e dentre estes motivos estariam a insatisfação com a qualidade do ensino escolar em razão de violência, a insegurança, a exposição a drogas e amizades indesejadas pelos pais e, por fim, o desejo de oferecer uma educação de qualidade para os filhos, explorando o potencial deles, além de proporcionar uma socialização mais ampla, com pessoas de todas as faixas etárias (BRASIL, 2014a, p. 27). Assim, o perfil das famílias interessadas em educação domiciliar seria de pais dispostos a investir tempo e recursos na formação intelectual de seus filhos, desejando participar mais ativamente desse processo.

Exaltando benefícios da educação domiciliar em detrimento da "educação conteudista" brasileira, Ricardo Dias comentou o seguinte:

[...] um dia, uma repórter perguntou assim ao meu filho: 'Você não acha que a professora está mais preparada que o seu pai e a sua mãe para the ensinar em casa?' [...] 0 meu filho, de 12 anos, respondeu: 'Talvez a professora esteja até mais preparada, mas, quando meus pais não sabem, nós vamos pesquisar e toda a família aprende junta'. Eu fiquei muito feliz, porque essa é uma constatação do meu filho, não

ao ingressarem em escolas que não consideram seu potencial e suas capacidades individuais e criativas, mas antes tentam enquadrá-las num sistema educacional rígido, conservador, anacrônico e sufocante. 0 conto é, assim, apresentado "às avessas", para provocar uma reflexão que suscite mudanças significativas em favor de uma educação verdadeira, edificante, que preserve na criança - no ser humano - a capacidade de sonhar, criar, transformar e se realizar. 
somente minha e de muitas famílias que estão aqui. (BRASIL, 2014a, p. 29)

Ricardo Dias justifica sua opção e de sua família pela educação domiciliar, dizendo que tentou, assim como outros pais, ter uma "escola melhor", mas se cansou de tentar e, agora, gostaria de ter outra opção. É possível, assim, afirmar que homeschooling é uma realidade no país, sendo uma modalidade de educação já praticada por famílias e também que há o desejo de pais que querem outra opção de ensino para os filhos que não passe, obrigatoriamente, pela escola.

O professor da Faculdade de Educação da Universidade de Brasília, Remi Castioni, ouvido na audiência pública, também teceu comentários em defesa das famílias que desejam educar seus filhos fora da escola. Para ele, a diversidade de meios e métodos educativos deve ser reconhecida e, tecnicamente, "não há segredo nenhum em educar um filho fora da escola". Citando a Escola da Ponte, em Portugal, idealizada por José Pacheco, diz que essa instituição conta "experiências fantásticas de processos de educação vivenciados no seio familiar com resultados expressivos" (BRASIL, 2014a, p. 32). O professor reconhece que o debate sobre a regulamentação legal da educação domiciliar permite a problematização e ajuda a discutir o que há de errado na escola porque, "se estivesse tudo bem, seguramente eu acho que nós não teríamos porque estar discutindo questões dessa natureza [...]" (BRASIL, 2014a, p. 32).

De toda a explanação do professor Remi Castioni, na audiência pública, foi possivel compreender que há uma preocupação instalada entre os estudiosos do tema a respeito da contrariedade à instituição escolar, que pode vir a ser formada com base nos argumentos dos adeptos da educação domiciliar.

Numa constatação, de certo modo, óbvia, André de Holanda Padilha Vieira infor- ma, na audiência pública, que o movimento pela educação em casa já existe. Ele baseia suas informações em pesquisas feitas sobre homeschooling, nos Estados Unidos e no Brasil, esclarecendo que, no Brasil, a "literatura acadêmica sobre o tema [é] limitada" (BRASIL, 2014a, p. 35). A maior parte de suas afirmações advém de sua própria pesquisa, ${ }^{6}$ realizada em 2012 com 62 pais brasileiros que são adeptos de educação domiciliar no país. Segundo ele, no entanto, a ANED estima que o número de pais educadores no Brasil esteja em torno de 600 a 2000 famílias. Através de sua pesquisa, ele pôde observar 117 crianças e adolescentes que são educados em casa. Com base no perfil demográfico dessas famílias, André Vieira diz que:

em média, [...] têm 37 anos, são casados, cristãos - a grande maioria [...], têm o nivel de escolaridade e renda familiar acima da média. Os pais [que participaram da pesquisa] - $80 \%$ - têm 12 anos ou mais de estudo [...]. E eles têm uma renda familiar de cerca de 3.700 reais. [...] é mais ou menos o dobro da média da renda familiar brasileira. Eles têm mais de uma motivação, [...]. Caráter, moralidade e socialização são as principais delas. [...]. E defendem a existência da escola pública. (BRASIL, 2014a, p. 39)

Para continuar tentando traçar o perfil desses pais que afastam a escola de suas biografias, André Vieira apresenta mais dados de sua pesquisa:

os pais que educam em casa no Brasil e que participaram da minha pesquisa gastam 183 reais por mês com educação em casa. É bem menos do que o custo da escola privada no Brasil e um pouco menos hoje do que o custo da educação básica pública brasileira. [...] Outro dado é que os pais estão combinando as abordagens da educação: $30 \%$ dos pais que participaram da

6 VIEIRA, André de Holanda Padilha. Escola? Não, obrigado: um retrato da homeschooling no Brasil. 2012. 77 f. Monografia (Graduação em Sociologia) - Faculdade de Ciências Sociais, Universidade de Brasília, UnB, Brasília, DF, 2012. 
pesquisa disseram que consideram a abordagem, o método que eles aplicam, eclético. Ou seja, eles estão tentando a educação clássica, a aprendizagem natural, unschooling, aprendizagem estruturada, vários métodos da educação em casa. E $84 \%$ dos pais disseram que educam em casa e que seguem uma aprendizagem estruturada com pelo menos quatro horas por dia de atividades planejadas por eles. Ou seja, é uma abordagem mais ou menos próxima daquela agenda de estudos da escola convencional. A idade média dos estudantes domiciliares cujos pais participaram da pesquisa é de oito anos, [...]. E 77\% dos pais educadores não são professores certificados. ${ }^{7}$ (BRASIL, 2014a, p. 39)

André Vieira, concluindo seu pensamento, com base no sociólogo canadense Bruce Arai, informa que "os pais que educam em casa estão [...] definindo uma nova cidadania [...] que seria baseada na importância da família e da participação pública" (BRASIL, 2014a, p. 41).

Durante a audiência pública, o presidente da Comissão de Legislação Participativa, deputado Lincoln Portela (PRB/MG), informou a participação de internautas e registrou a fala de alguns deles:

Edson Oliveira: "hoje em dia temos inúmeros recursos para aquisição de conhecimento. Não é mais necessário sair de casa para aprender, e a família aprende junto com a criança [...]. o governo não pediu à (sic) opinião pública para obrigar nossas crianças de quatro anos a frequentarem a escola". Diego 77: "a educação é para todos, e todos devem escolher o tipo de educação que creem ser a melhor". Márcio Barros: "educar crianças não diz respeito a dar emprego para professores. Os nossos filhos não podem ser utilizados com esse argumento". Ernani Moraes: “[...], por isso que não podemos brigar com a escola. Na verdade, temos até que ajudá-las com o nosso conhecimento e experiência na área de Educação Domiciliar". Márcio Barros: “[...] no Canadá, como exemplo,

7 A questão da certificação dos pais educadores ou da pessoa responsável pela educação domiciliar nas famílias, quando realizada por um terceiro, necessita de muito debate, tendo em vista a questão da valorização do Magistério, princípio constitucionalmente garantido. os pais que educam seus filhos em casa são mas (sic) envolvidos com a comunidade. Cerca de $98 \%$ participam ativamente da vida política, comparado com $93 \%$ dos pais de crianças em escolas privadas e cerca de $60 \%$ dos pais com crianças em escolas públicas". Márcio Barros: “a questão não é a eliminação das escolas e, sim, o direito dos pais de educar em casa para os pais que assim o desejam". (BRASIL, 2014a, p. 42, grifos meus)

Pela transcrição, é possivel notar que representantes da sociedade se manifestaram com argumentos favoráveis à educação domiciliar, aprovando a resistência à escola como um meio exclusivo de educação, o que comprovaria a necessidade de se discutir o assunto, bem como analisar os anseios daqueles que defendem a regulamentação da prática de homeschooling no Brasil.

A doutora em educação pela PUC/SP, Elizângela Treméa Fell, constatou que os pais que querem a regulamentação da educação domiciliar são a exceção e seria muito difícil legislar para a exceção, posto que, normalmente, legisla-se para a regra. Haveria, ainda, o problema da fiscalização: como saber se o ensino domiciliar está sendo ministrado? Segundo ela, "como vamos conseguir separar os pais que realmente querem educar [...] e os pais desleixados que não querem educar, mas não querem que o filho vá para a escola?" (BRASIL, 2014a, p. 45).

O pedagogo Fábio Schebella, preocupandose com a questão da socialização das crianças educadas em casa, informa que a ciência, os estudos e as pesquisas estariam mostrando que "é necessário que a criança, no seu desenvolvimento e na sua aprendizagem, se relacione", pois só haveria aprendizagem quando houvesse relacionamento. Mas, ensinar em casa, não impediria a socialização, já que a criança não deixaria de se relacionar com outros sujeitos. Além disso, ele exemplificou com sua própria experiência e convivência com pessoas que 
foram ensinadas em casa, especialmente por morar com uma família que estaria na terceira geração de crianças ensinadas em casa, sendo que nenhum desses indivíduos teria apresentado qualquer "problema social". Para ele, "até este momento, na história da humanidade, não existe qualquer fato que demonstre que ensinar em casa elimina a socialização" (BRASIL, 2014a, p. 49).

Segundo Fábio Schebella,

o ser social se constrói como tal enquanto interage com a sociedade ao seu redor, ou seja, se socializa de forma ativa no próprio meio social. Por que ensinar em casa não é um problema social? Porque a criança não é socializada exclusivamente nem na escola nem em casa. Nós todos somos socializados na sociedade. (BRASIL, 2014a, p. 49)

Para ilustrar sua defesa das famílias que excluem a escola de suas biografias, Fábio Schebella citou Paulo Freire que enaltecia sua educação em casa. 0 pedagogo, provavelmente, estaria se referindo à conhecida afirmação do educador pernambucano:

Fui alfabetizado no chão do quintal de minha casa, à sombra das mangueiras, com palavras do meu mundo e não do mundo maior dos meus pais. 0 chão foi o meu quadro-negro; gravetos, o meu giz. (FREIRE, 1989, p. 11)

Aproveitando-se do exemplo de Paulo Freire, Fábio Schebella acrescentou que:

se a criança ser ensinada em casa é um problema social, então Paulo Freire foi um problema social. Mas nós sabemos que não o foi. [...] o que eu conheço do Paulo Freire é um caso de amor com a educação domiciliar, porque ele falava de uma educação que não vem de cima para baixo, mas uma educação que acontece no nosso meio; [...] Ele falava que o aprendizado não é transferir conhecimento de uma cabeça para outra, mas é construir o conhecimento. E não é isso que vocês, pais, estão fazendo com os seus filhos, construindo conhecimento? [...] E o conhecimento vai estar sendo (sic) desenvolvido como um grupo, como uma família, como uma equipe, inclusive o conhecimento social. O conhecimento social não está nos livros, não está numa sala de aula, não está na ponta do giz. O conhecimento social está na sociedade. O conhecimento como um todo está no mundo ao nosso redor. E por isso, na minha opinião, e eu acredito que na da maioria das pessoas aqui, socialização não é um problema para a Educação Domiciliar. (BRASIL, 2014, p. 51-52)

Já para Alexandre Magno Fernandes Moreira, diretor jurídico da Associação Nacional de Educação Domiciliar (ANED), a família não tem o direito de educar os filhos; a família tem o dever de educá-los, conforme previsto na Constituição da República. Citando o livro "A criança terceirizada", de José Martins Filho, Alexandre Magno lembra que as famílias que resistem à obrigatoriedade da escola desejam não terceirizar a educação de seus filhos para a escola (BRASIL, 2014, p. 65).

Denota-se que a argumentação de Alexandre Magno está baseada em uma interpretação da legislação, segundo a qual a família se sobreporia ao Estado na determinação da melhor educação a ser dada aos filhos sem, contudo, questionar a instituição escolar como "vilã" ou eventual responsável pelo desejo de regulamentação legal da prática de homeschooling. Para ele, as famílias resistentes à escola obrigatória não pretendem combater o sistema escolar formal, mas apenas afastar seus filhos do que chamou de "hipertrofia da escola", pois hoje se exige dessa instituição funções que não lhe são próprias e que a escola não teria capacidade de dar conta como, por exemplo, a disciplina, o afeto, os limites, os conceitos morais, os exemplos éticos. Ao relegar essas tarefas à escola, [aí sim] "a imensa maioria das famílias brasileiras [estaria] cometendo [...] uma ilicitude grave de abandono afetivo, de abandono intelectual, de abandono moral com re- 
lação a seus filhos" (BRASIL, 2014, p. 54).

Um depoimento, contudo, extraído dessa audiência pública, reflete bem o que pensam e o que sentem os adeptos e defensores da homeschooling. Karenina Thomas relata sua educação domiciliar e não parece arrependida em não ter a escola em sua biografia.

Sou filha de um americano e uma norueguesa, mas sou nascida e criada no Brasil. Por opção dos meus pais eu fui educada pelo método do ensino domiciliar. [...] Minha família tem uma história interessante com a educação. 0 meu bisavô foi educador [...] discípulo [de] John Dewey [...]. O meu avô [...]teve uma escolarização normal [...]. O [...] meu pai [...] acabou sendo um missionário e querendo ir para fora do seu país [...]. Ele conheceu a minha mãe aqui no Brasil 30 anos atrás. Eles acabaram ficando aqui, tiveram seis filhos e optaram pelo ensino domiciliar, não só para poder ensinar os filhos no idioma dele, que era o inglês, mas também por questões religiosas. [...] [Meus pais] pegaram um currículo dos Estados Unidos, que já era usado para o ensino em casa, [...] e eles nos ensinaram com esse método, mas não se fixaram a isso, [...]; usaram outros métodos para a alfabetização, para as outras áreas de aprendizado. [...] Assim, eu fui alfabetizada com três anos. [...] Minha mãe se formou como professora com esse curso que usaram dos Estados Unidos, e tivemos um acompanhamento, mas não do governo brasileiro. Acho que eles conseguiram se safar (sic) desse jeito por serem estrangeiros e, portanto, não estavam sujeitos à fiscalização nacional. Mas eles usaram métodos de avaliações anuais do governo da Califórnia, [...] as provas de avaliação anual que todas as escolas públicas e privadas do Estado de Califórnia usavam. [...]. (BRASIL, 2014, p. 58-59)

E continua seu relato autobiográfico, enfatizando o cotidiano de sua experiência com homeschooling, bem como as motivações e justificativas para afastar a escola de sua história de vida.

Foi uma experiência muito realizadora para mim [...]. Essa parte da socialização, [...] foi uma experiência muito rica, [...], [pois] interagirmos com gente de vários países e de várias áreas do Brasil. [...] Além disso, também tivemos as atividades extracurriculares, como natação e balé. [...]. Também para terminar o ensino médio eu fiz uma prova nos Estados Unidos, [...] Relatando alguns dos benefícios [...]: sou autodidata e desde os meus seis anos eu não precisei de um acompanhamento de um professor, mas só da checagem básica, de quando fazíamos as provas, [...]; os laços familiares foram muito fortes, foram uma parte muito importante para mim; a segurança também foi um aspecto importante, pois meus pais se sentiam muito mais seguros comigo em casa do que fora, por várias razões [...]. Para mim, a educação não era algo fixo, no horário escolar; estávamos aprendendo o tempo inteiro, na sala de aula, em casa, brincando. A educação foi uma experiência contínua em casa. Outra coisa foram os idiomas: eu nunca estudei o português, [...] eu o peguei pela convivência, pela interação e pela socialização que eu tive. E também aprendi o norueguês em casa com minha mãe e aprendi o espanhol com os amigos de países latino-americanos. A flexibilidade também para as necessidades dos alunos foi uma coisa marcada para mim. No tocante ao uso abrangente de materiais, tivemos muito mais opções de uso dos materiais educacionais. A atenção individualizada também foi muito importante, o desenvolvimento do caráter e a parte do ensino religioso que, para mim, continua sendo muito importante e muito boa. [...] Mas foi uma experiência própria. Para os outros pode vir a não ser tão boa. Resumindo, na minha experiência, a educação é um investimento de tempo, é um investimento financeiro, mas realmente vale a pena. E quero muito ver que no Brasil isso venha a ser um direito mais aparente, para que os pais tenham isso. [...]. (BRASIL, 2014, p. 60-61)

O relato biográfico de Karenina entra "como contrabando no universo científico" (BOURDIEU, 2005, p. 183), pois permite, a partir da história de uma vida, estabelecer conclusões sobre um determinado fenômeno social, que é, neste estudo, a motivação daqueles que resistem à escola e optam pela educação através de homeschooling. Através do relato de vida de Karenina, foi possivel perceber o cotidiano 
da família, cujos filhos não frequentam a escola e, assim, compreender o fenômeno homeschooling nesse cotidiano.

Rafael Morais, um adolescente que também foi educado em casa, relata suas impressões sobre a socialização dos adeptos de homeschooling e reforça os argumentos em defesa das famílias resistentes à hegemonia da instituição escolar:

Tenho 18 anos e estudei na escola. [...] Eu sempre fui autodidata. Com o tempo, na escola, eu fui perdendo isso. A escola, em vez de me beneficiar, foi "acabando comigo" [...]. Aqui nós não estamos falando mal da escola. A gente só quer o direito de poder ser educado em casa. Eu digo que, para mim, foi muito melhor ser educado em casa. Eu vejo minhas irmãs, que também fazem o ensino familiar, é bem melhor para elas serem educadas em casa. A gente pode focar, como disse o Ricardo, naquilo que a gente é bom (sic). Eu queria ressaltar uma fala do Fábio, que, para mim, foi muito boa. Ele disse que a gente não (sic) é socializado. 0 pessoal sempre fala desse tema de socialização, que, se você sai da escola, você não faz amizades e tal. Quem estuda em casa, quem tem esse ensino familiar, tem muito mais facilidade de se relacionar com as outras pessoas. Geralmente as pessoas que estudam em casa tem muito mais facilidade de se relacionar. (BRASIL, 2014a, p. 72-73)

Opiniões, como as desses adolescentes, tiveram por objetivo demonstrar, aos deputados do Congresso Nacional, numa tentativa de sensibilizá-los, que a educação domiciliar não é prejudicial à socialização daqueles que optam por essa modalidade e que todos estariam satisfeitos com a opção dos pais pela prática de homeschooling (KLOH, 2014, p. 91).

Em outra audiência pública, ${ }^{8}$ dessa vez realizada na Comissão de Educação, em 12 de novembro de 2013 , outros pais puderam relatar suas biografias e defender sua opção pela

8 Os relatos desta audiência pública foram colhidos a partir do áudio disponibilizado pela Câmara dos Deputados, que pode ser consultado em: <http://imagem.camara.gov.br/internet/audio /Resultado.asp?txtCodigo=46500>. Acesso em: 26 nov. 2014. educação domiciliar, em detrimento da escola obrigatória. Em que pese o fato de muitos defensores de homeschooling terem sido ouvidos nesta audiência pública, procurou-se dar ênfase às falas das famílias praticantes desta modalidade de educação, a fim de não nos desviarmos do objetivo deste estudo, que é compreender, através de relatos autobiográficos, as motivações para a resistência à escola.

Dentre os ouvidos nessa audiência pública, o professor do Departamento de Educação da Universidade Estadual de Maringá e doutor pela Unicamp, Luiz Carlos Faria da Silva, que relatou a história pessoal de sua família, pois, casado com uma pedagoga, pai de dois adolescentes, é defensor da liberdade dos pais de exercerem a modalidade de educação domiciliar, uma vez que ele mesmo pratica essas ideias com seus filhos, que estão fora da escola desde 2007 (KLOH, 2014, p. 96). Segundo ele, seus filhos foram matriculados na escola aos 7 anos de idade, mas, com o tempo, apareceram conflitos entre o modo como a educação era organizada em casa e na escola (BRASIL, 2013).

Outro pai ouvido na Comissão de Educação foi Josué Peixoto Bueno, que mantém seus dez filhos em educação domiciliar. Relatando exemplo de seu próprio filho que, após frequentar a escola, "voltou batendo nos irmãos e xingando" (BRASIL, 2013), defendeu, emocionadamente, esta modalidade de educação como um direito das famílias. Sua esposa, Darcília Bueno, na qualidade de mãe, esclareceu que a educação domiciliar é pautada por "famílias bem estruturadas e que amam seus filhos e querem o melhor para eles" (BRASIL, 2013).

Traçado o perfil biográfico das famílias que resistem à escola e defendem a regulamentação da educação domiciliar no país, foi possível conhecer o que pensam e o que querem os homeschoolers, com base no recorte das falas autobiográficas, expostas e analisadas neste 
estudo. Resta saber onde essa resistência vai levar.

\section{No fim... o que esperam da resistência}

Olhar o que essas famílias fazem e ouvir o que dizem torna possível afirmar que a educação domiciliar, regulamentada ou não, já existe e é praticada no Brasil. Em que pese a inexistência de regulamentação legal, o que angustia e deixa inseguras as famílias adeptas de homeschooling, a prática da educação domiciliar se apresenta como uma realidade posta no Brasil. E os pais que a praticam anseiam pela permissão de terem outra opção para educar seus fihos, que não passe pela escola obrigatória. Não querem a extinção da escola, mas a coexistência da educação em casa e na escola.

As motivações pessoais das famílias são de naturezas diversas. Passam por questões religiosas e financeiras; por questões referentes ao direito fundamental da família em escolher o tipo de educação que deseja para seus filhos; pelo desejo, enfim, de participarem mais ativamente da educação de seus filhos através de espaços formativos diferentes da escola. Os

\section{Referências}

BOURDIEU, Pierre. A ilusão biográfica. In: FERREIRA, Marieta de Moraes; AMADO, Janaína. (Orgs.). Usos e abusos da história oral. Rio de Janeiro: Editora FGV, 2005. p. 183-191.

BRASIL. Lei $\mathbf{n}^{\circ}$ 9.394, de 20 de dezembro de 1996 (LDBEN). Disponivel em: <http://www.planalto.gov. br/ccivil_03/leis/19394.htm>. Acesso em: 27 mar. 2014.

BRASIL. Congresso Nacional. Câmara dos Deputados. Projeto de Lei $\mathbf{n}^{\circ}$ 3.179, de 2012. Acrescenta parágrafo ao art. 23 da Lei $n^{\circ}$ 9.394, de 1996, de diretrizes e bases da educação nacional, para dispor sobre a possibilidade de oferta domiciliar da educação básica. Brasília, DF: Diário da Câmara depoimentos colhidos demonstram que essas famílias são constituídas por pais dispostos a investir tempo e recursos na formação intelectual dos filhos.

As justificativas dessas famílias para a resistência à hegemonia da escola estão baseadas em fatores como a insatisfação com a qualidade do ensino escolar; a violência, a insegurança, a exposição às drogas e amizades “indesejadas" que podem estar presentes no ambiente da escola; a possibilidade de utilizar diferentes métodos de ensino e dar atenção individualizada aos filhos; além do desejo de oferecer uma educação de qualidade e de proporcionar uma socialização mais ampla.

Conclui-se que, embora ainda seja uma minoria a se manifestar sobre homeschooling, este é um fenômeno crescente no país e hoje é liderado por famílias que resistem à escola, mas não querem se sentir ameaçadas pela insegurança de um eventual processo judicial que lhes imponha a pena do abandono intelectual e da perda da guarda de seus filhos, motivos que, por si só, já demonstram a necessidade de se discutir o assunto e analisar os anseios daqueles que defendem a regulamentação da prática de homeschooling.

dos Deputados, 9 fev. 2012. p. 1178.

BRASIL. Congresso Nacional. Câmara dos Deputados. Áudio da Audiência Pública na Comissão de Educação (12/11/2013). Disponivel em: <http://imagem.camara.gov.br/internet/audio/Resultados.asp?txtCodigo $=46500>$. Acesso em: 26 nov. 2013.

BRASIL. Congresso Nacional. Câmara dos Deputados. Comissão de Legislação Participativa. Educação Domiciliar. Brasília, DF: Câmara dos Deputados, Edições Câmara, 2014 (2014a).

BRASIL. Congresso Nacional. Câmara dos Deputados. Regimento Interno da Câmara dos Deputados. 12. ed. Brasília, DF: Câmara dos Deputados, Edições 
Câmara, 2014 (2014b).

CANÁRIO, Rui. Escola - crise ou mutação? In: AAVV. Espaços de Educação, Tempos de Formação. Lisboa: Fundação Calouste Gulbenkian, 2002. p. 141-151.

FLACH, Simone de Fátima. O direito à educação e sua relação com a ampliação da escolaridade obrigatória no Brasil. Ensaio: aval. pol. públ. Educ., Rio de Janeiro, v. 17, n. 64, p. 495-520, set. 2009.

FREIRE, Paulo. A importância do ato de ler: em três artigos se completam. 23. ed. São Paulo: Cortez Editora, 1989.

GERSON, Brasil. História das ruas do Rio. 6. ed. Rio de Janeiro: Ed. Bem-Te-Vi, 2015.

ILLICH, Ivan. Sociedade sem escolas. 2. ed. Petrópolis, RJ: Vozes, 1973.

KLOH, Fabiana Ferreira Pimentel. Homeschooling no Brasil: a legislação, os projetos de lei e as decisões judiciais. 2014. 235 f. Dissertação (Mestrado em Educação) - Faculdade de Educação, Universidade Católica de Petrópolis, Petrópolis, 2014.

MANACORDA, Mario Alighiero. História da Educação: da antiguidade aos nossos dias. 13. ed. São Paulo: Cortez, 2010.

ORTHOF, Sylvia. Maria vai com as outras. 3. ed. São Paulo: Ática, 1985.
PORTILHO, Gabriela. Educação fora da escola. Revista Crescer. Edição Digital, 14/04/2015. Disponivel em: <http://revistacrescer.globo.com/Voce-precisa-saber/noticia /2015/04/ educacao-fora-da-escola.html>. Acesso em: 21 abr. 2016.

RIBEIRO, Álvaro Manuel Chaves. 0 ensino doméstico e a organização escolar: um contributo sociológico -organizacional sobre a realidade portuguesa. 2011. 344 f. Dissertação (Mestrado em Educação) - Ciências da Educação, Universidade do Minho, Portugal, 2011.

VASCONCELOS, Maria Celi Chaves. A casa e os seus mestres: a educação no Brasil de Oitocentos. Rio de Janeiro: Gryphus, 2005.

Vozes femininas do Oitocentos: o papel das preceptoras nas casas brasileiras. In: LÔBO, Yolanda; FARIA, Lia. (Orgs.). Vozes femininas do Império e da República. Rio de Janeiro: Quarter; FAPERJ, 2008. p. 19-45.

VIEIRA, André de Holanda Padilha. "Escola? Não, obrigado": um retrado da homeschooling no Brasil. 2012. 77 f. Monografia (Graduação em Sociologia) Faculdade de Ciências Sociais, Universidade de Brasília, UnB, Brasília, DF, 2012.

Recebido em: 22.04.2016 Aprovado em: 30.06 .2016

Fabiana Ferreira Pimentel Kloh é doutoranda em Educação. Universidade do Estado do Rio de Janeiro/UERJ. Integra o Grupo de Pesquisa História e Memória das Políticas Educacionais no Território Fluminense. Mestre em Educação pela Universidade Católica de Petrópolis/RJ. Orientadora Escolar da Rede Municipal de Ensino de Petrópolis/RJ.

E-mail: fabianapimentel@yahoo.com.br.

Estrada União e Indústria, 7299 bloco B apto. 108, Nogueira - Petrópolis/RJ CEP: 25.730-725 